\title{
In response to The role of smartphones in encouraging physical activity in adults
}

This article was published in the following Dove Press journal: International Journal of General Medicine

\section{Aaina Mittal' \\ Shyam Gokani' \\ Alexander Zargaran ${ }^{2}$ \\ Javier Ash' \\ Georgina Kerry ${ }^{3}$ \\ Dara Rasasingam'}

'Department of Medicine, Imperial College School of Medicine, Imperial College London, London, 'Department of Medicine, St. George's, University of London, London, ${ }^{3}$ Department of Medicine, University of Birmingham Medical School, Birmingham, UK
Correspondence: Aaina Mittal Department of Medicine, Imperial College School of Medicine, Imperial College London, Exhibition Road, Kensington, London SW7 2AZ, UK Email aaina.mittall2@imperial.ac.uk

\section{Dear editor}

We read with great interest the article by Stuckey et al ${ }^{1}$ entitled "The role of smartphones in encouraging physical activity in adults" recently published in the International Journal of General Medicine.

As the article identifies, "lack of physical activity is a global public health issue", so finding ways of encouraging it is essential to better health outcomes worldwide. Bearing this in mind and recognising the article has set groundwork for prospective exploration in the areas it addresses, scope for future research in this area can be identified.

First, this review was carried out in adults aged over 18 years. Considering the prevalence of childhood obesity is increasing all over the world, ${ }^{2}$ it would be worth investigating strategies that would be useful in a younger population too. Proving efficacy with, for example, smartphone apps may promote developers to create apps that target this issue at a younger age. This has the potential of improving healthcare for many generations to come, by preventing future diseases that a lack of physical activity may have caused.

Second, only smartphone-based interventions were considered. However, the field of information technology is vast, with many different forms making their way into daily lives. The efficacy of interventions via other platforms, such as smart watches, tablets and laptops, may provide further evidence to promote the use of information technology in encouraging physical activity.

Third, leading on from what the last two points have alluded to, the role of information technology in encouraging other lifestyle changes that may lead to better health, may help to lower the cost on current healthcare systems, by functioning as a form of preventative medicine.

In conclusion, this article has addressed an important and timely issue. There is vast scope for more research in this area, as this letter has identified. If enough evidence is revealed to support the use of information technology in encouraging better lifestyle habits, it has the potential to make effective and efficient contributions to the field of preventative medicine.

\section{Disclosure}

The authors report no conflicts of interest in this communication. 


\section{References}

1. Stuckey MI, Carter SW, Knight E. The role of smartphones in encouraging physical activity in adults. Int J Gen Med. 2017;10:293-303.

2. Lifshitz F. Obesity in children. J Clin Res Pediatr Endocrinol. 2008;1(2):53-60. 


\section{Authors' reply}

Melanie I Stuckey'

Shawn W Carter ${ }^{2}$

Emily Knight ${ }^{3}$

'Research and Academics, Ontario Shores Centre for Mental Health Sciences, Whitby, ON, Canada, ${ }^{2}$ Eating Disorder Residential Program, Ontario Shores Centre for Mental Health Sciences, Whitby, ON, Canada, ${ }^{3}$ Faculty of Health Sciences, University of Western Ontario, London, ON, Canada

Correspondence: Melanie I Stuckey

Ontario Shores Centre for Mental Health Sciences, 700 Gordon Street, Whitby, ON LIN5S9, Canada

Tel + I 9054304055 ext 6945

Email stuckeym@ontarioshores.ca

\section{Dear editor}

Thank you for providing the opportunity to respond to the letter written by Mittal et al in response to our paper titled "The role of smartphones in encouraging physical activity in adults." We generally agree with their comments, but add considerations for each of their three suggestions.

First, we purposefully limited the scope of our review to the adult population as we believe there should be significant differences in the approach to working with children and adolescents. Smartphone applications (apps) intended to improve the health of children may be beneficial, but considering the heightened risk of developing negative cognitions about food, physical activity and body image at this age, app developers should be mindful of promoting and/ or maintaining healthy attitudes and behaviors and should avoid targeting behaviors that are symptoms of disordered eating including calorie counting, restriction and weight tracking. We believe the following should be considered in the development of apps to encourage physical activity in children and adolescents:

1. Appropriate exercise for children is play. To increase play in children we need to provide opportunity for safe environments and regular times to play. Physical activity should be promoted as fun and leisure, not as a calorieexpending behavior.

2. Children and adolescents are in a state of development and do not yet have adult cognitive abilities, particularly the ability to think abstractly and to be flexible. Rather, they tend to be rule bound and concrete. As such, apps suggesting behaviors such as tracking or reaching certain activity or calorie goals may inadvertently encourage unhealthy behaviors and attitudes. Since the onset of mental health conditions is at its peak during childhood and adolescence, with half of all lifetime cases starting before the age of 14 years and three-quarters before the age of 24 years, ${ }^{2}$ it should be strongly considered that children or adolescents with symptoms of anxiety, obsessive compulsive disorder or disordered eating could end up using these apps to extremes, negatively impacting their health and growth.

3. Children and adolescents are not all able to make informed decisions and may use such applications in a way that could end up being harmful to their cognitive development and physical growth. Children learn (unhealthy) mainstream attitudes toward food and weight at a very young age. Five-year-old children already associate a diet with food restriction, weight loss and thinness ${ }^{3}$ and eating disorders have been diagnosed in children as young as 5 years old. ${ }^{4}$ Thus, app developers need to be mindful of the message relayed to the children and efforts should be made to promote positive attitudes and behaviors. Adults need to ensure that the lived environment is conducive to safe play and need to be mindful of their own responsibility for and influence over their children's behaviors. Mindfully developed apps or other information technology may be able to support adults to manage their children's play or to support children directly to encourage physically active play.

Second, we limited the scope of our review to smartphone technology for feasibility, but agree that other information technology may be useful in encouraging physical activity. It is likely that the most successful interventions will be dependent upon the characteristics of the intervention itself (e.g., the behavior change techniques) rather than the information technology platform per se, although particular features of the information technology may facilitate behavior change. As we had suggested in our paper, behavior change theories may need to be adapted to fit technology-based interventions. ${ }^{5}$ However, with the technology field evolving so quickly, interventions specific to certain technologies may become quickly obsolete. This is especially important when considering long-term maintenance of physical activity behaviors. Third, we agree that if we are able to adequately harness technology to encourage physical activity, there is a strong potential for health promotion, chronic disease prevention and management, and overall healthcare cost savings. However, we are also mindful that much of the resistance to exercise and physical activity is attributed to societal norms and there is a need to shift attitudes to more positively view physical activity as a fun or rewarding experience rather than 
a punishment related to food, body weight and body image. While changing these cognitions and norms is an extremely challenging undertaking, it has potential to cause lasting and meaningful change and technology could be used to support this change.

In conclusion, we strongly support the use of technology to encourage physical activity, but recognize the complexities surrounding the behavior and the process of change. Moving forward, it will be up to researchers and developers to create apps that target appropriate behaviors to encourage physical activity and hopefully to promote positive attitudes about participating in physical activity. Particular caution should be taken when developing apps to maintain the element of leisure (play for children) and to be mindful of inadvertently promoting disordered eating and exercise behaviors and cognitions.

\section{Disclosure}

The authors report no conflicts of interest in this communication.

\section{References}

1. Stuckey MI, Carter SW, Knight E. The role of smartphones in encouraging physical activity in adults. Int J Gen Med. 2017;10:293-303.

2. Kessler RC, Berglund P, Demler O, Jin R, Merikangas KR, Walters EE. Lifetime prevalence and age-of-onset distributions of DSM-IV disorders in the National Comorbidity Survey Replication. Arch Gen Psychiatry. 2005;62(6):593-602.

3. Abramovitz BA, Birch LL. Five-year-old girls' ideas about dieting are predicted by their mothers' dieting. J Am Diet Assoc. 2000;100(10): $1157-1163$.

4. Pinhas L, Nicholls D, Crosby RD, Morris A, Lynn RM, Madden S. Classification of childhood onset eating disorders: a latent class analysis. Int J Eat Disord. 2017;50(6):657-664.

5. Riley WT, Rivera DE, Atienza AA, Nilsen W, Allison SM, Mermelstein $R$. Health behavior models in the age of mobile interventions: are our theories up to the task? Transl Behav Med. 2011;1(1):53-71.

Dove Medical Press encourages responsible, free and frank academic debate. The content of the International Journal of General Medicine 'letters to the editor' section does not necessarily represent the views of Dove Medical Press, its officers, agents, employees, related entities or the International Journal of General Medicine editors. While all reasonable steps have been taken to confirm the content of each letter, Dove Medical Press accepts no liability in respect of the content of any letter, nor is it responsible for the content and accuracy of any letter to the editor.

\section{Publish your work in this journal}

The International Journal of General Medicine is an international, peer-reviewed open-access journal that focuses on general and internal medicine, pathogenesis, epidemiology, diagnosis, monitoring and treatment protocols. The journal is characterized by the rapid reporting of reviews, original research and clinical studies across all disease areas.
The manuscript management system is completely online and includes a very quick and fair peer-review system, which is all easy to use. Visit http://www.dovepress.com/testimonials.php to read real quotes from published authors. 